\title{
Low-noise microvolt level calibrator for measurement of performance of biosignal recording systems
}

\author{
TAPANI KORHONEN and LAURI VILJANTO \\ University of Jyväskylä, Jyväskylä, Finland
}

\begin{abstract}
A calibrator, the noise level of which is below the noise level generated in the preamplifier system, was needed for testing and development of a multichannel recording system. A multichannel preamplifier head assembly was used for recording cortical, subcortical, and cerebellar slow potentials and multiunit activity in freely moving cats and restrained rabbits. An inexpensive, battery-powered, lownoise voltage signal generator for calibration of the preamplifiers is described. The circuit provides a square-wave output at a frequency of 10 or $1000 \mathrm{~Hz}$, and the peak-to-peak $(p-p)$ amplitude can be selected at 10,100 , or $1000 \mu \mathrm{V}$. The measured output noise of the calibrator is below $2 \mu \mathrm{V}(\mathrm{p}-\mathrm{p}, 0.1-$ $6000 \mathrm{~Hz}$ ). The frequency and amplitude values can be easily adapted for different purposes by changing a few component values. An amplified (gain 1,000×) test output for direct oscilloscope monitoring is included in the calibrator circuit.
\end{abstract}

In biological recording systems, there is usually a preamplifier stage that defines the performance of the measurement system. The voltage gain of such a preamplifier is usually preset to a low value, because the primary purpose of the preamplifier usually is to act as a voltage-tocurrent converter and to provide high impedance input against the recording electrode.

The circuit described here was initially designed for testing the properties of a low-noise FET preamplifier system based on an instrumentation amplifier circuit (INA110, Burr-Brown, Tucson, AZ). The noise level of the preamplifier system in our configuration is about $5 \mu \mathrm{V}$ peak-topeak $(\mathrm{p}-\mathrm{p})$ at the recording bandwidth of $0.1-6000 \mathrm{~Hz}$. A compact multichannel preamplifier assembly (4-8 channels) made of these instrumentation amplifier circuits is used in our laboratory for simultaneous recording of field, evoked slow potential, and multiunit responses in several brain structures (e.g., hippocampus, cortex, cerebellar cortex) of freely moving cats and restrained rabbits. Using instrumentation amplifiers as preamplifiers also allows for the use of two-wire electrodes either for bipolar differential recording or as a monopolar recording system if a reference electrode is connected to one of the inputs.

In general, the noise level depends on the type of instrumentation amplifier selected (bipolar or FET input). Testing the noise and signal performance of a preamplifier system is difficult if a signal or pulse generator that can provide a test signal, the noise level of which is below that of the measurement system, is not available. Available

Correspondence should be addressed to $\mathrm{T}$. Korhonen, Department of Psychology, University of Jyväskylä, P. O. Box 35, SF-40351 Jyväskylä, Finland (e-mail: tkorhone@jyu.fi). commercial EEG calibrators do not yield low microvoltlevel test signals, and some earlier test generators have been mainly intended for equipment check-out (e.g., Epperson \& Wilson, 1985; Helmer, 1986). The calibrator circuit described here produces a symmetrical square-wave output at two selected frequencies $(10$ and $1000 \mathrm{~Hz})$ and at three output voltage levels $(10,100$, and $1,000 \mu \mathrm{V})$. These values are appropriate for testing our recording system, but the frequencies and output levels can be easily adjusted to other purposes by changing the values of a few components in the circuit.

The schematics of the circuit are shown in Figure 1. The battery power-current source consists of two 9 - $\mathrm{V}$ batteries with low-voltage-drop regulators (LP 2951, National Semiconductor, Santa Clara, CA) that give stabilized operating voltage $( \pm 5 \mathrm{~V})$ to the calibrator. Low-noise operational amplifiers (OP27, Precision Monolithics, Santa Clara, CA) have been used in all stages of the circuit. The manufacturer's specifications for OP27 show a noise level of about $0.2 \mu \mathrm{V}(\mathrm{p}-\mathrm{p}$ at $10 \mathrm{kHz})$.

The first two amplifiers act as a signal generator producing a symmetrical square wave, after which voltagedividing resistors give direct output or, alternatively, provide input to an amplifier that amplifies the signal by $1,000 \times$ for monitoring purposes (e.g., oscilloscope). All resistors in the circuit are metal thin-film precision resistors. Due to the low level of output signal after the voltagedividing resistor network, it is important to keep the length of the connecting wires as short as possible. One of the preferred solutions is to use a printed circuit board to avoid the problem of excessive wiring and, hence, possible oscillatory feedback sources. Figure 2 shows the layout of the circuit board used in our calibrator.

The actual waveform of the output of the calibrator when the $10-\mu \mathrm{V}$ output level and $10-\mathrm{Hz}$ frequency are 

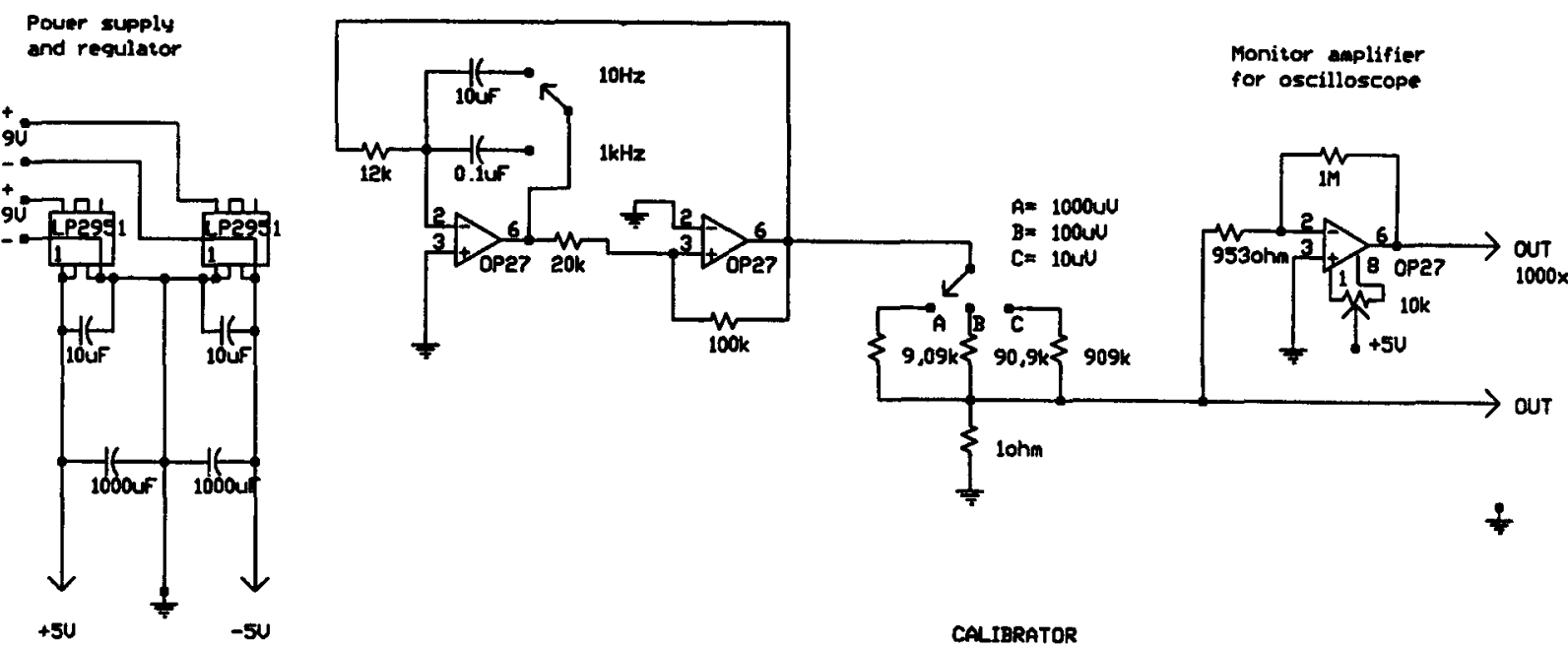

Figure 1. The circuit schematics of the calibrator. The first and second operational amplifier (OP27) form a square-wave generator circuit, the frequency of which can be changed by selecting different values for the capacitor (here 0.1 and $10 \mu F$ ) and the resistor (here $12 \mathrm{k} \Omega$ ). The signal is then fed to the voltage divider in which the amount of attenuation can be selected with a multiposition switch. The monitor amplifier has a gain of $1,000 \times$, and a trimmer $(10 \mathrm{k} \Omega)$ is used for adjusting the offset level of the output.

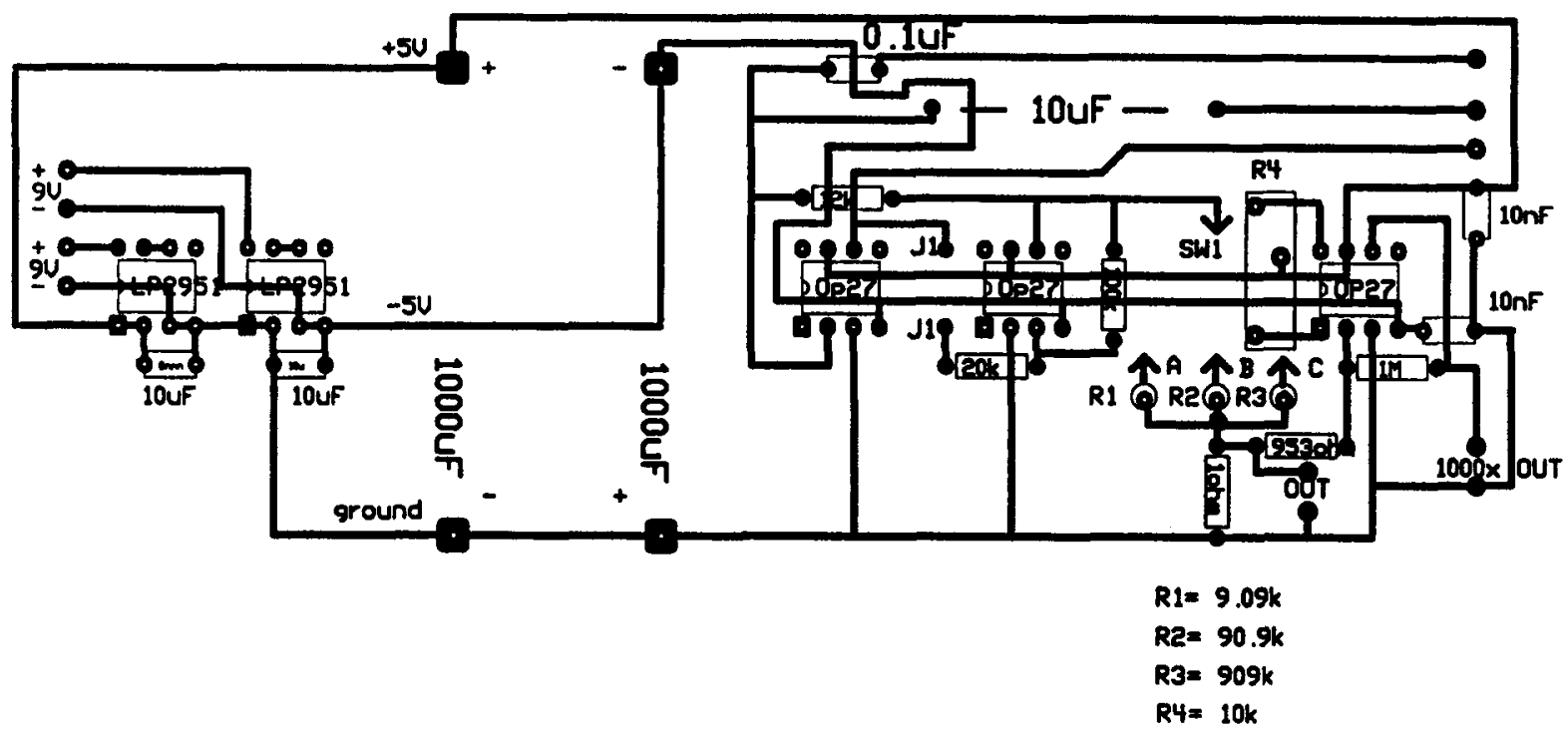

Figure 2. The printed circuit-board design for the calibrator. The critical point for the output noise is the site of the dividing resistor network $(9.09 \mathrm{k} \Omega, 90.9 \mathrm{k} \Omega, 909 \mathrm{k} \Omega$, and $1 \Omega$ resistors). The placements of the resistors $R 1, R 2$, and R3 are critical in preventing excessive oscillations in the circuit. That is why they are in a vertical position and the free ends of these resistors (A, $B$, and C) and the point SW1 are wired directly to the selector switch using shielded cables. The points marked as J1 are connected together with a jumper wire. 


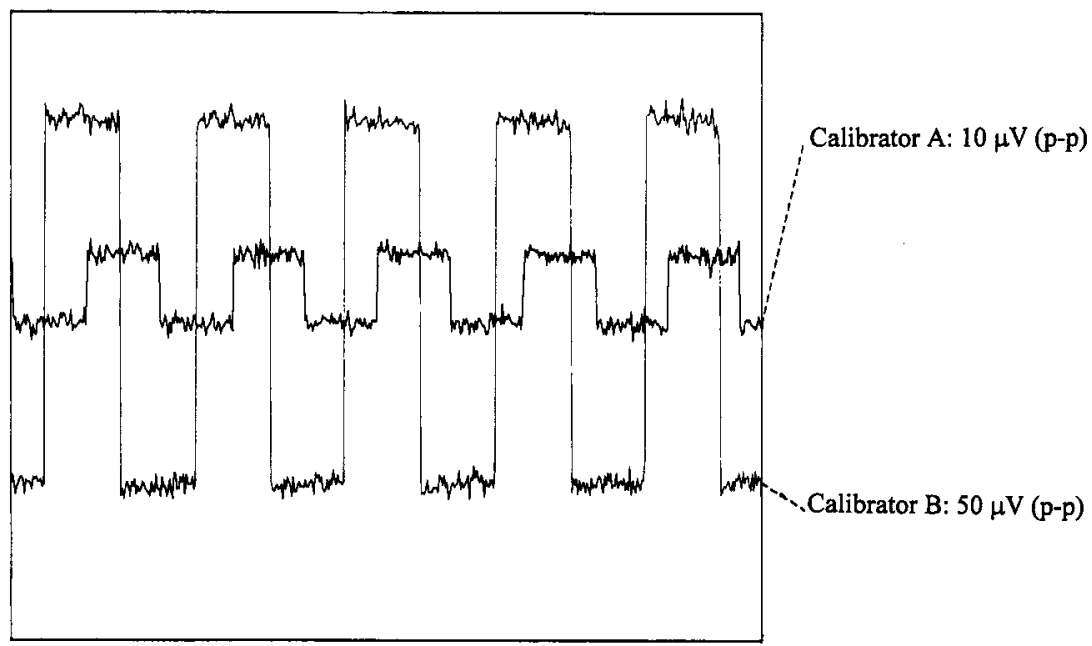

Figure 3. This figure shows the output of the calibrator design (Calibrator $\mathbf{A}$ ), for a comparison with that of a commercial calibrator (Calibrator B, Bio-Logic, Precision Square-Wave Calibrator) when a $10-\mu \mathrm{V}$ and $10-\mathrm{Hz}$ signal is driven through the preamplifier system made of INA110 instrumentation amplifiers. The preamplifier gain is $100 \times$, and the bandwidth is $0.1-6000 \mathrm{~Hz}$. The smallest calibrating signal of the commercial calibrator is $50 \mu \mathrm{V}(\mathrm{p}-\mathrm{p})$.

chosen is shown in Figure 3. In this recording example, an instrumentation amplifier (INA110) is used as the preamplifier with a gain of $100 \times$ and recording bandwidth is set to 0.1 to $6000 \mathrm{~Hz}$. The noise level of the INA1 10, according to manufacturer specifications, is $1 \mu \mathrm{V}(\mathrm{p}-\mathrm{p}, 0.1-10 \mathrm{~Hz})$. For purposes of comparison, Figure 3 shows the lowest available level ( $\mathrm{p}-\mathrm{p}$ of $50 \mu \mathrm{V})$ of the output of one rather expensive commercial calibrator (BioLogic, Precision Square-Wave Calibrator).

\section{REFERENCES}

EPPERSON, R. K., \& WILSON, A. J. (1985). A simple, inexpensive stimulus waveform generator. Behavior Research Methods, Instruments, \& Computers, 17, 388-390.

HELMER, R. J. (1986). A test-signal generator for low-frequency instrumentation. Behavior Research Methods, Instruments, \& Computers, 18, 372-376.

(Manuscript received May 28, 1996;

revision accepted for publication November 13, 1996.) 